\title{
PENDAMPINGAN IBU HAMIL TRIMESTER III MEMPENGARUHI KEBERHASILAN PRAKTIK PEMBERIAN ASI DI TANGERANG
}

\author{
*Erna Mesra \\ ernamesra@gmail.com
}

\begin{abstract}
Abstrak
Air Susu Ibu adalah makanan terbaik bagi bayi. ASI eksklusif adalah pemberian ASI tanpa makanan dan minuman tambahan pada bayi berumur 0-6 bulan. Menyusui sejak dini mempunyai dampak yang positif bagi ibu maupun bayinya. Manfaat memberikan ASI bagi ibu menjalin kasih sayang dan mengurangi perdarahan pasca melahirkan, mempercepat pemulihan ibu, menunda kehamilan, mengurangi risiko terkena kanker payudara, dan merupakan kebahagiaan bagi ibu (Depkes RI, 2011). Teknik menyusui cara memberikan ASI pada bayi dengan perlekatan dan posisi ibu dan bayi dengan benar. Praktik menyusui dilakukan dalam suasana yang santai bagi ibu dan bayi. Tujuan untuk mengetahui pengaruh pendampingan ibu hamil trimester III terhadap kemampuan praktik pemberian ASI Jenis penelitian Quasi Eksperimen dengan rancangan Statistik Group Comparison pre dan post-test. Hasil Ada Perbedaan signifikan pengetahuan ASI sebelum dan sesudah pendampingan pada kelompok intervensi didapatkan mean 16,89 dan t test 13,116 dan $p$ value 0.000 . Perbedaan keterampilam praktik pemberian ASI secara signifikan sebelum dan sesudah pendampingan mean 12,00 dan t test 3,851, $p$ value 0,000 ada perbedaan signifikan kemampuan praktik pada kelompok intervensi Saran: bidan meningkatkan mutu pelayanan kesehatan melalui penyuluhan tentang persiapan menyusui sejak usia hamil trimester III untuk menyusui bayi dan dipastikan memberikan ASI Ekslusif pada bayi sampai umur 2 tahun

Kata kunci : ibu hamil trimester III, praktik pemberian ASI

*Poltekkes Kemenkes Banten
\end{abstract}




\section{Pendahuluan}

Pemberian ASI eksklusif pada bayi 0-6 bulan di Indonesia pada tahun 2014 target program pada tahun 2014 sebesar $80 \%$, secara nasional cakupan pemberian ASI eksklusif sebesar 52,3\% belum mencapai target. Menurut provinsi,hanya terdapat satu provinsi yang berhasil mencapai target yaitu Provinsi Nusa Tenggara Baratsebesar 84,7\% sedangkan pencapaian target terendah yaitu Provinsi Jawa Barat 21,8\%, Papua Barat 27,3\%, dan Sumatera Utara 37,6\% (Profil Kesehatan Indonesia, 2014).

Cakupan pemberian ASI eksklusif pada bayi usia 0-6 bulan secara Nasional $80 \%$ di Provinsi Banten $65 \%$ artinya ibu yang tidak memberikan ASI eksklusif persentase $35 \%$ (Profil Kesehatan Indonesia, 2014).Prevalensi ASI eksklusif berdasarkan Riset Kesehatan Dasar (Riskesdas) tahun 2010 masih rendah menjadi 15,3\%. Cakupan pemberian ASI eksklusif pada bayi usia 0-6 bulan di DKI Jakarta memiliki persentase $62,73 \%$ sedangkan yang tidak memberikan ASI eksklusif memiliki persentase $37,27 \%$ (Profil Kesehatan Indonesia, 2013).

Berdasarkan Survey Demografi dan Kesehatan Indonesia (SDKI) tahun 2012 menunjukkan Angka Kematian Bayi (AKB) 32 kematian per 1000 kelahiran hidup dan kematian balita adalah 40 kematian per 1000 kelahiran hidup dan mayoritas kematian bayi terjadi pada neonatus. Pada tahun 2012 Angka kematian bayi tertinggi di Indonesia diduduki oleh Gorontalo dan Papua Barat dengan jumlah kematian 67 jiwa dan 74 jiwa dari 1.283 jiwa (SDKI, 2012).
Tingginya angka kematian bayi dan neonatal disebabkan oleh masih rendahnya status gizi pada ibu hamil, masih rendahnya pemberian Air Susu Ibu (ASI) Eksklusif, masih tingginya angka kesakitan terutama diare, asfiksia, dan Infeksi Saluran Pernapasan Akut (ISPA) (Depkes RI, 2009).

Menyusui sejak dini mempunyai dampak yang positif baik bagi ibu maupun bayinya. Manfaat memberikan ASI bagi ibu tidak hanya menjalin kasih sayang tetapi dapat mengurangi perdarahan setelah melahirkan, mempercepat pemulihan kesehatan ibu, menunda kehamilan, mengurangi risiko terkena kanker payudara, dan merupakan kebahagiaan tersendiri bagi ibu (Depkes RI, 2011).

Memberi ASI pada bayi merupakan proses alami sebagai kewajiban seorang ibu yang mengasuh anaknya. Karena ASI merupakan makanan utama untuk bayi umur 0-6 bulan pertama kehidupannya. Proses alami untuk memberikan ASI sudah dimulai saat terjadi kehamilan, karena bersama dengan hamil, payudara telah disiapkan sehingga setelah bayi lahir ibu bisa segera memberikan ASI pada bayinya.

\section{Metode Penelitian}

Jenis penelitian adalah penelitian eksperimen kuasi (Quasi experiment) dengan rancangan penelitian Two Group Pretest Posttest. (Notoatmodjo, 2005). 
Penelitian ini melakukan pre dan pos test pada kelompok eksperimen maupun kelompok control pada waktu yang bersamaan, dimana hanya kelompok eksperimen saja yang mendapat perlakuan. Pretest Intervensi Postest Teknik sampling yang digunakan pada penelitian ini menggunakan non probability sampling dengan pendekatan purposive sampling, yaitu didasarkan pada suatu pertimbangan tertentu yang dibuat oleh peneliti sendiri,berdasakan ciri atau sifat-sifat populasi yang sudah diketahui sebelumnya(Notoatmodjo, 2010). Pada penelitian ini dibagi menjadi 2 (dua) kelompokyaitu kelompok intervensi dan kelompok kontrol, yang masing-masing kelompok ada 36 responden, jadi total sampelnya ada 72 responden.Pengambilan sampel berdasarkan kriteria inklusi dan eksklusi. Data dalam penelitian ini adalah data primer. Data primer diambil secara langsung kepada responden dengan menggunakan instrument berupa kuesioner dan daftar tilik. Teknik pengambilan sampel menggunakan simple randomsampling. Analisa dengan analisa univariat dan Analisis Bivariat Menggunakan uji dependen $t$ tes

\section{Hasil}

Penelitian ini dilakukan di Bidan Praktek mandiri Tangerang Tentang Pengaruh Pendampingan Ibu Hamil Trimester III Terhadap Praktik Pemberian Asi Di Bidan Praktik Mandiri Tangerang Tahun 2016. Metode penelitian Penelitian ini menggunakan metode penelitian eksperimen semu (quasi
eksperimen).Selama kehamilan Trimester III, ibu diberikan penyuluhan kesehatan tentang ASI, teknik menyusui yang benar. Pada masa postpartum 2 jam, ibu sudah mulai didampingi dalam proses pemberian ASI sesuai dengan teknik menyusui yang telah dijelaskan sebelumnya. Pada masa postpartum 6 jam, dilakukan penilaian ulang untuk memastikan ibu sudah menyusui dengan baik. Pada 6 hari post partum dilakukan penilaian dengan menggunakan daftar tilik praktik menyusui.

Tabel 1

Distribusi Frekuensi Responden berdasarkan Karakteristik di BPM Tangerang

\begin{tabular}{|l|c|c|c|c|}
\hline \multirow{2}{*}{ Karakteristik } & \multicolumn{2}{|l|}{$\begin{array}{l}\text { Kelompok } \\
\text { Kontrol }\end{array}$} & \multicolumn{2}{l|}{$\begin{array}{l}\text { Kelompok } \\
\text { Intervensi }\end{array}$} \\
\cline { 2 - 5 } & Frek & $\%$ & Frek & $\%$ \\
\hline Umur & & & & \\
\hline$<20->30$ & 2 & 5,56 & 1 & 2,77 \\
\hline $20-30$ & 34 & 94,44 & 35 & 97,23 \\
\hline Pendidikan & & & & \\
\hline $\begin{array}{l}\text { Rendah } \\
(, S D, S M P)\end{array}$ & 8 & 22,23 & 12 & 33,33 \\
\hline $\begin{array}{l}\text { Tinggi(SMA, } \\
\text { PT) }\end{array}$ & 28 & 77,77 & 24 & 66,67 \\
\hline Pekerjaan & & & & \\
\hline Tidak bekerja & 26 & 72,22 & 28 & 77.77 \\
\hline Bekerja & 10 & 27,73 & 8 & 22,23 \\
\hline \multicolumn{1}{|c|}{ Total } & 36 & 100 & 36 & 100 \\
\hline
\end{tabular}

Berdasarkan tabel 1 ditunjukkan bahwa 94,44\% responden umur 20-30, pada kelompok perlakuan 97,23\% Pendidikan responden $77,77 \%$ adalah SMA kelompok control dan pada kelompok perlakuan $66,67 \%$ Pekerjaan $72,22 \%$ responden tidak bekerja pada kelompok kontrol dan $77,77 \%$ pada kelompok intervensi 
Tabel 2

Distribusi Frekuensi Responden berdasarkan Pengetahuan sebelum dan sesudah Pendampingan di BPM Tangerang tahun 2016

\begin{tabular}{|l|c|c|c|c|c|c|c|c|}
\hline \multirow{3}{*}{ Pengetahuan } & \multicolumn{9}{|c|}{ Kontrol } & \multicolumn{4}{c|}{ Intervensi } \\
\cline { 2 - 9 } & \multicolumn{3}{|c|}{ Pre-tes } & \multicolumn{2}{c|}{ Pos-tes } & \multicolumn{2}{c|}{ Pre-tes } & \multicolumn{2}{c|}{ Pos-tes } \\
\cline { 2 - 9 } & $\mathrm{N}$ & $\%$ & $\mathrm{~N}$ & $\%$ & $\mathrm{~N}$ & $\%$ & $\mathrm{~N}$ & $\%$ \\
\hline Kurang & 15 & 41,66 & 12 & 33,33 & 23 & 63,88 & 15 & 41,66 \\
\hline Baik & 21 & 58,34 & 24 & 66,37 & 13 & 36,12 & 21 & 58,34 \\
\hline & 36 & 100 & 36 & 100 & 36 & 100 & 36 & 100 \\
\hline Praktik & & & & & & & & \\
\hline Kurang & 16 & 44,44 & 12 & 33,33 & 27 & 75,00 & 0 & 0 \\
\hline Baik & 20 & 55,56 & 24 & 66,37 & 9 & 25,00 & 36 & 100 \\
\hline Total & 36 & 100 & 36 & 100 & 36 & 100 & 36 & 100 \\
\hline
\end{tabular}

Dari hasil pre-test pengetahuan diketahui bahwa 23 responden $(63,88 \%)$ kategori kurang pada kelompok Eksperimen sedangkan kelompok kontrol 15 responden $(41,66 \%)$ kategori kurang. Dengan Demikian rata rata nilai pengetahuan adalah kategori kurang
Dari hasil post-test praktik menyusui diketahui bahwa 36 responden $(100 \%)$ kategori baik pada kelompok Eksperimen sedangkan kelompok kontrol 24 responden $(66,37 \%)$ kategori baik. Dengan Demikian rata rata nilai praktik menyusui adalah kategori baik

Tabel 4

Hasil pengujian beda rata rata pre-test dan pos-test Pengetahuan Responden tentang ASI

\begin{tabular}{|c|c|c|c|c|c|c|}
\hline Pengetahuan & \multicolumn{3}{|c|}{ Kontrol } & \multicolumn{3}{c|}{ Intervensi } \\
\hline & Mean & t-tes & P Value & Mean & t-tes & P Value \\
\hline Pre-test & 3.25 & & & 3.25 & & \\
\hline Post-tes & 11,53 & 1.805 & 0,075 & 16.89 & 13.116 & 0,000 \\
\hline Praktik & \multicolumn{3}{|l}{} & Mean & t-tes & P Value \\
\hline & Mean & t-tes & P Value & Mean & \\
\hline Pre-test & 1.75 & & & 1,75 & & 0,000 \\
\hline Post-tes & 11.58 & 1.792 & 0,078 & 12.00 & 3.851 & \\
\hline
\end{tabular}

Dari tabel diatas dapat diketahui bahwa Pengetahuan nilai t-test $=13.116$ dan $\mathrm{p}$ value 0,000 , ada perbedaan signifikan perubahan pengetahuan antara kelompok perlakuan yang sudah diberi modul dan pendampingan tentang ASI dengan kelompok kontrol yang tidak 
diberi pendidikan kesehatan dengan mempelajari modul dan pendampingan sejak hamil trimester III tentang ASI dan praktik menyusui. Praktik menyusui nilai t-test $=3.851$ dan nilai $\mathrm{p}$ value 0,000 ada perbedaan signifikan, dan perubahan keterampilan antara kelompok intervensi yang diberi modul tentang ASI dengan kelompok kontrol yang tidak diberi modul dan pendampingan pada responden..

\section{Pembahasan}

\section{Pengetahuan Responden}

Berdasarkan hasil penelitian responden pada kelompok intervensi peningkatan pengetahuan setelah diberi penyuluhan dan modul diketahui nilai rata rata pre-test 3.69 dan post-test meningkat 16.89. Hasil nilai awal pengetahuan tentang ASI dengan menggunakan uji $t$ test di peroleh nilai $\mathrm{p}$ Value 0,000 artinya ada perbedaan secara bermakna. Pada Kelompok intervensi kemudian dilakukan post test terjadi peningkatan 13,20 secara statistik maupun empiris merupakan peningkatan nilai rata rata pengetahuan yang bermakna .

Pada kelompok kontrol mengalami peningkatan dari 3.25 menjadi 11.53 ( meningkat 8,28) dengan nilai $\mathrm{p}$ value 0,75 secara statistik dan secara empiris merupakan peningkatan nilai rata rata pengetahuan namun tidak bermakna. Kurangnya pengetahuan post test dapat disebabkan karena responden mendapat informasi tentang ASI dari lingkungan sekitarnya. Menurut Notoatmodjo (2012), pengetahuan (knowledge) adalah hasil tahu dari manusia yang sekedar menjawab pertanyaan "What". Pengetahuan merupakan hasil dari tahu, dan ini terjadi setelah orang melakukan penginderaan terhadap suatu objek tertentu. Penginderaan, penciuman, rasa, dan raba. Pengatahuan atau kognitif merupakan domain yang sangat penting dalam membentuk tindakan seseorang (overt behavior). Peningkatan nilai rata rata nilai pengetahuan dari pre-test ke post-test pada kelompok perlakuan membuktikan bahwa kelompok perlakuan yang menerima penyuluhan dan membaca modul tentang ASI dapat menerima dengan baik. Jika pengetahuan responden lebih luas dan mempunyai pengalaman tentang praktek pemberian ASI baik dialami sendiri, maupun dilihat dari teman , tetangga atau keluarga maka akan lebih terinspirasi untuk melaksanakan praktek pemberian ASI.

\section{Praktik pemberian ASI}

Berdasarkan hasil penelitian responden pada kelompok intervensi peningkatan kemampuan praktik setelah diberi penyuluhan dan modul serta dilakukan pendampingan praktik langsung menyusui bayinya diketahui nilai rata rata pre-test 2.06 dan posttest meningkat 12,00. Hasil nilai awal praktik pemberian ASI dengan menggunakan uji $t$ test di peroleh nilai $\mathrm{p}$ value 0,000 artinya ada perbedaan secara bermakna. Pada 
kelompok intervensi setelah dilakukan post-test terjadi peningkatan 9,04 secara statistik maupun empiris merupakan peningkatan secara signifikan dengan melaksanakan praktik pemberian ASI secara tepat dan benar. Pada kelompok kontrol mengalami peningkatan dari 1.75 menjadi 11.58 ( meningkat 8,73 ) dengan nilai $\mathrm{p}$ value 0,78 secara statistik dan secara empiris merupakan peningkatan nilai rata rata praktik namun tidak bermakna. Meningkatkan keterampilan post-test dapat disebabkan karena responden mendapat pendampingan langsung dari bidan dan lingkungan sekitarnya. Pengetahuan yang didapatkan ibu tentang pemberian ASI akan dipraktekkan dalam kehidupan seharihari. Sesuai dengan teori Notoatmodjo, 2012. Cara memperoleh pengetahuan lebih sistematis, logis dan ilmiah yang disebut metode ilmiah. Kemudian metode berfikir induktif bahwa dalam memperoleh kesimpulan dilakukan dengan mengadakan observasi langsung, membuat catatan terhadap semua fakta sehubungan dengan objek yang diamati. Materi yang di berikan selama pendampingan dalam modul yang dapat meningkatkan pengetahuan dan keterampilan responden sejalan dengan penelitian Khumaidah 2011 dalam Novita 2013 Penggunaan metode diskusi dengan media ajar jenis leaflet efektif untuk meningkatkan hasil belajar mata pelajaran biologi pada siswa kelas XI SMA Wedang Demak. Menurut peneliti bila seorang ibu mendapat pendampingan atau bimbingan untuk persiapan menyusui sejak hamil maka ibu akan termotivasi dan menimbulkan sikap positif dan

\section{Hubungan antara Pengetahuan dengan praktik Pemberian ASI pada Ibu Menyusui}

Pengetahuan merupakan unsur yang sangat penting bagi terbentuknya perilaku seseorang dan pengetahuan juga merupakan langkah awal dari pembuat keputusan yang seeorang pada akhirnya akan berperilaku sesuai dengan pengetahun yag diperolehnya. (Notoadmodjo,2010) Ada hubungan yang signifikan antara pengetahuan dengan pemberian ASIsesuai penelitian Atabik,2013 ada hubungan pengetahuan dengan pemberian ASI pada Ibu menyusui. Ibu menyusui mempunyai pengetahuan yang baik tentang ASI mereka baru sampai pada tahu, pemahaman tentang ASI masih rendah sehingga ibu-ibu berpengetahuan baik tentang ASI,ada pendapat bahwa ASI nya tidak cukup untuk memenuhi kebutuhan bayinnya, kebisaan keluarga mencampur ASI dengan formula perilaku ibu dipengaruhi oleh lingkungan. Banyak ibu yang berhenti menyusui sebelum bayi berusia 6 bulan karena kurangnya pengetahuan ibu tentang teknik menyusui yang baik dan benar (Wulandari,2010) Ibu yang pengetahuan baik akan memberikan ASI Eksklusif kepada bayi mereka. Pendidikan juga menjadi salah faktor terhadap pengetahuan ibu. 
(Notoadmodjo, 2008). Pengetahuan dipengaruhi oleh faktor pendidikan formal, sangat erat hubungannya dengan pendidikan, dimana diharapkan pendidikan yang tinggi semakin luas pengetahuannya. Menurut teori WHO yang dikutip oleh Notoatmodjo (2007), salah satu bentuk objek kesehatan dapat dijabarkan oleh pengetahuan yang diperoleh dari pengalaman sendiri, kemudian melakukan praktek sesuai pengetahuan dan keterampilan.

\section{Simpulan}

1. Ada Perbedaan signifikan pengetahuan ASI sebelum dan sesudah pendampingan pada kelompok intervensi didapatkan mean 16,89 dan $t$ test 13,116 dan $p$ value 0.000 .

2. Perbedaan keterampilam praktik pemberian ASI secara signifikan sebelum dan sesudah pendampingan mean 12,00 dan $t$ test $3,851, p$ value 0,000 ada perbedaan signifikan kemampuan praktik pada kelompok intervensi

\section{Daftar pustaka}

Andreani, Anna. 2013. Faktor-Faktor yang Berhubungan dengan Perilaku Pemberian ASI di Puskesmas Kecamatan Kebayoran Lama, Jakarta Selatan Tahun 2013. Skripsi FKM UI.

Alyani, Delima S. 2011. Hubungan Karakteristik Ibu Terhadap Perilaku Pemberian ASI
Eksklusif di wilayah kerja

Puskesmas Cipondoh

Tangerang Tahun 2011. Skripsi FKM UI.

Aritonang, Citra. 2011. Hubungan karakteristik, Pengetahuan, Sikap dan Dukungan Keluarga Ibu dengan Perilaku Pemberian ASI Eksklusif di Puskesmas Kecamatan Bandar Huluan Kabupaten Simalungun Provinsi Sumatera Utara tahun 2011. Skripsi FKM UI.

Depkes RI. 2006. Rencana Strategi Departemen Kesehatan. Jakarta : Depkes RI.

Depkes RI. 2007. Pelatihan Konseling Menyusui. Jakarta

Depkes RI. 2009. Kebijakan departemen Kesehatan tentang Peningkatan Pemberian Air Susu Ibu (ASI) Pekerja Wanita. Pusat Kesehatan Kerja Depkes RI.

Depkes RI. 2011.

http://www.depkes.go.id/downlo ads/PROFIL_DATA_KESEHAT AN_INDONESIA TAHUN_201

1.pdf. Diakses tanggal 18

Februari 2016 pukul 19.00 WIB

Dewi, Rita N. 2010 Faktor-Faktor yang Berhubungan dengan Perilaku Pemberian ASI Eksklusif di Puskesmas Kecamatan Ciracas Jakarta Timur Tahun 2010. Skripsi FKM UI.

Ferawati. 2010. Faktor-Faktor yang Berhubungan dengan Perilaku Pemberian ASI Eksklusif pada anak umur 6-24 bulan di Kelurahan Pondok Cina 
Kecamatan Beji Kota Depok Tahun 2010. Skripsi FKM UI.

Hakim, R. 2012. Faktor-Faktor yang Berhubungan dengan Pemberian ASI Eksklusif Pada Bayi Usia 6-12 bulan di Wilayah Kerja Puskesmas Nabire Kabupaten Nabire.

http://lib.ui.ac.id/file?file=digita l/20320761-S

Ramla\%20Hakim.pdf. Di akses tanggal 12 Februari 2015 pukul $21.00 \mathrm{WIB}$.

Helmi, Maizu. 2010. Analisis Hubungan Pengetahuan, Sikap Ibu dan Faktor Lainnya Terhadap Pemberian ASI Eksklusif Pada Bayi Usia 0-12 bulan di Wilayah Kerja Puskesmas IV Koto Kinali Tahun 2010. Skripsi FKM UI.

Huka, Christina Legawati. 2010. Faktor-Faktor yang Berhubungan dengan Perilaku Pemberian ASI Eksklusif di Puskesmas Kecamatan Cijeruk Kabupaten Bogor Provinsi Jawa Barat Tahun 2010. Skripsi FKM UI.

Kristiyanasari, W. 2011 ASI, Menyusui dan Sadari. Yogjakarta : Nuha Medika Manfaat DHA Untuk Kehamilan dan buah

hatiandbidanku.com http://bida nku.com/manfaat-dha-untukkehamilan-dan-buah-hatianda\#ixzz4AULwtiPN Diakses tanggal 18 Maret 2016 pukul 15.00 WIB
Notoatmodjo, Soekidjo. 2012. Metodologi Penelitian. Jakarta : Rineka Cipta

Notoatmodjo, Soekidjo. 2012. Promosi Kesehatan dan Perilaku Kesehatan. Jakarta : Rineka Cipta

Nurini, LP. 2009. Faktor-Faktor yang Berhubungan dengan Perilaku Ibu Multipara dalam Pemberian ASI Eksklusif di Poli KIA Puskesmas Kecamatan Cilincing Tahun 2009. Skripsi FKM UI.

Nursalam. 2008. Metode Penelitian Kesehatan. Jakarta : Salemba Medika

Riksani, R. 2012. Keajaiban ASI (Air Susu Ibu). Jakarta : Dunia Sehat

Riset Kesehatan Dasar. 2013. Badan Penelitian dan Pengembangan Kesehatan Kementerian Kesehatan RI Tahun 2013.

Syebrina, Vidya Wati. 2011 Faktorfaktor yang Berhubungan dengan Perilaku Ibu Dalam Pemberian ASI Ekslusif di Kota Pariaman Provinsi Sumatera Barat. Skripsi FKM UI.

Walyani, Elisabeth. 2015.

Perawatan Kehamilan dan Menyusui Anak Pertama Agar Bayi Lahir dan Tumbuh Sehat. Yogyakarta : Pustaka Baru Press 